\title{
DISPERSAL AND DISEASE GRADIENTS OF ANTHER-SMUT INFECTION OF SILENE ALBA AT DIFFERENT LIFE STAGES ${ }^{1}$
}

\author{
BERNADETTE M. RochE ${ }^{2}$ \\ Department of Biology, University of North Carolina, Chapel Hill, North Carolina 27599-3280 USA \\ Helen Miller Alexander \\ Department of Botany and Department of Systematics and Ecology, University of Kansas, \\ Lawrence, Kansas 66045-2106 USA \\ ARLAN D. MALTBY ${ }^{3}$ \\ Department of Systematics and Ecology, University of Kansas, Lawrence, Kansas 66045-2106 USA
}

Abstract. Given the increased recognition of the importance of spatial aggregation of infected individuals on disease spread, we used a field experiment to examine spore dispersal and disease transmission at increasing distances from an inoculum source in a well-studied system, the herbaceous plant Silene alba, infected by the anther-smut fungus Ustilago violacea. Two different life stages (vegetative and floral) were examined. We measured spore deposition on flowers and, as an analog of dispersal to vegetative plants, in small vials on the ground. Spore and disease gradients (number of spores or proportion of plants infected as a function of distance) were best fit with the classic power law, $Y=a D^{-b}$. The slope parameter, $b$, was similar for spore dispersal gradients of vegetative $(b=-2.38)$ and flowering plants $(b=-1.91)$. However, at every distance measured, the proportion of flowers with spores was higher than the proportion of ground vials with spores, indicating overall higher relative spore dispersal to flowering plants. We also determined that disease gradients for flowering plants were more shallow $(b=-0.07)$ than spore dispersal gradients, and vegetative infection was more spatially restricted than floral infection (no infection beyond $3.2 \mathrm{~m}$ for vegetative plants while floral infection was detected up to $11.2 \mathrm{~m}$ ). The relationship between spore dispersal and disease incidence was linear for vegetative plants and curvilinear for flowering plants, with limiting returns on disease after a low threshold number of spores deposited. Overall, our study suggests that the limited dispersal of spores is likely to be important in the aggregation of diseased plants in nature; such aggregation of inoculum in turn can increase or decrease disease spread depending on how much inoculum is needed to cause infection.

Key words: anther-smut disease; plant-pathogen; Silene alba; spore and disease spread; Ustilago violacea.

\section{INTRODUCTION}

Disease transmission depends on two fundamental processes: dispersal of infective propagules and successful infection of hosts by those propagules. In the case of sessile hosts, a common net result of these processes is that diseased individuals are spatially aggregated (Pielou 1965, Burdon 1987, van den Bosch et al. 1988, Augspurger 1990). Dispersal processes contribute to the development of disease foci because dispersal is strongly distance dependent. However, disease foci could also develop despite extensive spore dispersal if susceptible host genotypes are aggregated or if factors of the physical environment that influence

\footnotetext{
${ }^{1}$ Manuscript received 21 April 1994; revised 12 December 1994; accepted 21 December 1994; final version received 12 January 1995.

${ }^{2}$ Present address: Biology Department, Vassar College, Poughkeepsie, New York 12601 USA.

${ }^{3}$ Present address: Department of Plant Pathology, University of Missouri, Columbia, Missouri 65211 USA
}

infection are patchily distributed (Augspurger and Kelly 1984). Without experimental manipulation, the processes responsible for clumping cannot be distinguished.

Separation of distance-based effects of dispersal from factors affecting successful infection is also an important first step in the incorporation of spatial patterns into ecological models of disease. An essential component of spatially explicit epidemiological models is information on how infectious units disperse in space. Although diffusion models have been used, knowledge of the contact distribution (i.e., the probability that a disease propagule released at one location will be deposited at another location) is preferable, especially since long-distance dispersal can occur and greatly alter disease spread (Mollison 1977). Spore dispersal gradients have been used successfully to estimate contact distributions in modelling the spread of plant pathogens; the high sensitivity of these models to variation in the sport dispersal function emphasizes 
the importance of this component (van den Bosch 1988).

In addition to focusing on the process of spore dispersal, the quantitative relationship between spore deposition and disease incidence should be considered. A nonlinear relationship between number of spores and proportion of plants that become infected is likely because a minimum number of spores may be required for successful infection and, at some higher number of spores, increased spore deposition may not lead to an increase in frequency of infection. The relationship between spore dispersal and successful disease establishment is of practical use: although disease incidence may be ultimately of more interest, measurement of spore deposition may be technically easier in some situations.

We used the fungus Ustilago violacea, which causes anther-smut disease in the plant Silene alba, to explore spatial patterns of spore dispersal and disease spread. In a previous study of $S$. alba, diseased plants were more aggregated than the underlying healthy population (Real et al. 1992). When diseased plants were introduced into a healthy field population, spore deposition and disease incidence were higher close to the inoculum than far from the inoculum, suggesting distance-restricted dispersal (Alexander 1990b). However, genotypic variation in host resistance (Alexander 1989), combined with localized seed dispersal, suggests that the plant population could be acting as a clumped resource base for the pathogen if susceptible genotypes are aggregated. Furthermore, infection can occur on both vegetative and flowering plants (Baker 1947, Alexander 1990 b), with the spore dispersal of the former assumed to be passive and the latter primarily the result of visits from insect vectors. Such different modes of transmission may produce different spatial patterns of disease.

The Silene alba-Ustilago violacea system has become a model system for theoretical and empirical studies of how different modes and rates of transmission affect whether host and pathogen coexist, both at the level of the local population (Alexander and Antonovics 1988, Alexander 1990a, Thrall and Jarosz $1994 a, b$, Thrall et al. 1994) and at the level of metapopulations (Alexander 1990a, Antonovics et al. 1993). With the exception of the metapopulation studies (Antonovics et al. 1993), however, theoretical work in this system does not consider the spatial pattern of healthy and diseased plants and their effect on disease spread. The increasing recognition that diseased individuals are clumped in space and that nonrandom transmission alters the numerical dynamics of host and pathogen (Hassell et al. 1991, Holt 1993) argues for increased attention to spatial patterns of disease spread. We therefore conducted a field experiment to determine: (1) the effect of distance from inoculum source on spore deposition and disease incidence, (2) the relationship between spore deposition and disease inci- dence, and (3) the effect of mode of transmission on spore deposition and disease incidence.

\section{STUDY ORGANISMS}

Silene alba (Miller) Krause (=Melandrium album, $S$. pratensis, and $S$. latifolia), white campion, is a dioecious short-lived perennial, which was introduced to North America from Eurasia in the early 1800s (McNeill 1977). S. alba grows along roadsides or other disturbed habitats. Infection by the anther-smut fungus, Ustilago violacea (Pers) Fuckel [= Microbotryum violacea (Pers) G. Deml and Oberw.], causes both male and female plants to produce staminate flowers with anther sacs filled with diploid fungal spores (teliospores). Anther-smut disease is a sterilizing infection: diseased male flowers contain no pollen, and the ovary is aborted prior to ovule maturation in diseased female flowers. Spores dispersed to healthy flowers may germinate and undergo meiosis; a dikaryon capable of infecting a plant is produced when meiotic products of opposite mating types conjugate (Baker 1947, Fischer and Holton 1957).

The white flowers of $S$. alba open at dusk, remain open all night, and begin to wilt during the late morning. They produce a strong perfumed scent at night, and produce nectar at the base of a long narrow corolla tube. Bees, moths, flies, and butterflies visit flowers of $S$. alba; insects that visit diseased flowers prior to visiting healthy flowers may act as spore vectors (Baker 1947, Alexander 1990a).

\section{Methods}

\section{Linear experimental populations}

Four replicate linear experimental populations (=gradients) consisting of healthy plants and a focus of diseased plants were established in summer 1990 at Mountain Lake Biological Station (MLBS) (Pembroke, Virginia) to simulate anther-smut spore dispersal and disease spread in linear roadside populations of $S$. alba (Fig. 1). The $16 \mathrm{~m}$ long $\times 1.6 \mathrm{~m}$ wide gradients were located in open fields at least $80 \mathrm{~m}$ from other gradients or other sources of diseased plants. Within each gradient, a 40 row $\times 4$ column grid was established with $0.4 \mathrm{~m}$ between each point on the grid. Only two of the four points within each of the 40 rows were randomly selected as plant locations. Each plant location contained a cluster of plants of differing developmental stages: two early-stage seedlings that had germinated during the course of the experiment (seedlings), two late-stage seedlings at least $14 \mathrm{~d}$ past germination (rosettes), and two flowering plants (of same sex and similar size and flower number). This design allowed the comparison of dispersal and disease gradients among life stages of $S$. alba. One member of each flowering plant pair was randomly designated as a tester plant from which flowers were sampled for spore deposition, and the other plant was designated as a nontester plant 
(no flower removals; inspected visually for disease development). The sex ratio of flowering plants was $\approx 1$ : 1. Diseased flowering plants were placed at eight randomly chosen locations within eight rows only (rows 5-12); these diseased plants served as the source of inoculum for subsequent spread. Seedlings and rosettes were arranged around the diseased plants as described above for healthy plants. Each gradient was partitioned into 10 four-row zones, so that there were two disease zones (zones 2 and 3), two zones adjacent to disease zones (zones 1 and 4), and six zones each at increasing distance from the inoculum source. The distance from the center of each zone to the center of the nearest disease zone was used to look at the relationships between distance from disease zone and spore dispersal or disease incidence.

Experimental plants came from seed collected in $\mathrm{Au}-$ gust 1989 from a healthy population in Giles County, Virginia. Flowering plants were started from seed at the Duke University greenhouse in April 1990 and transplanted into $180-\mathrm{cm}^{2}$ pots at MLBS in May 1990. Seeds used to produce rosettes were germinated in 100$\mathrm{cm}^{2}$ pots at MLBS. All rosettes were between 14 and $28 \mathrm{~d}$ old when placed in the gradients. Seeds used to produce seedlings were placed into $4 \mathrm{~cm}$ diameter $\times$ $21 \mathrm{~cm}$ deep pots (cone-tainers) within the gradients and germinated within $14 \mathrm{~d}$. Flowering plants used as disease source plants were inoculated as 8 -d-old seedlings by being soaked overnight at $17^{\circ} \mathrm{C}$ in a sporidial suspension of crossed strains of opposite mating type of $U$. violacea.

Once per week from 21 July 1990 to 16 August 1990 at $1600 \mathrm{~h}$, small vials (diameter $=1.5 \mathrm{~cm}$ ) containing $1 \mathrm{~mL} \mathrm{50 \%} \mathrm{ethyl} \mathrm{alcohol} \mathrm{were} \mathrm{set} \mathrm{out} \mathrm{at} \mathrm{soil} \mathrm{level} \mathrm{in}$ gradients 2 and 4 to collect passively dispersed fungal spores (one vial per location in rows $1-2$ and 15-40; two vials per location in rows 3-14). Vials were removed and sealed by 0930 the next morning. Later that day at 1400 , a flower was removed from each flowering tester plant in all four gradients and placed in a vial. To suspend any spores deposited on the flower, each flower was shredded in $1 \mathrm{~mL} \mathrm{50 \%} \mathrm{ethyl} \mathrm{alcohol} \mathrm{and}$ then agitated at top speed on a Vortex for $1 \mathrm{~min}$. The vial was sealed after removal of the flower and stored for later spore counts (volume per vial $\approx 0.8 \mathrm{~mL}$ ). Two counts of spore concentrations were performed for each ground and flower vial by using a hemacytometer (the vial was agitated for $1 \mathrm{~min}$ just prior to counting). Prior to counting, the volume of each vial was brought to 1 $\mathrm{mL}$ with an aqueous solution of toluidine blue $(2 \mathrm{mg} /$ $\mathrm{mL}$ ) to increase the visibility of the spores under the microscope. Due to slight variation in initial volume, adjusting the volume of all vials to $1 \mathrm{~mL}$ with the toluidine blue introduced some random variation causing us to potentially underestimate the number of spores. Spore counts were converted to spore number per millilitre (Tuite 1969), which gives a direct estimate of number of spores per flower. The spore count meth-

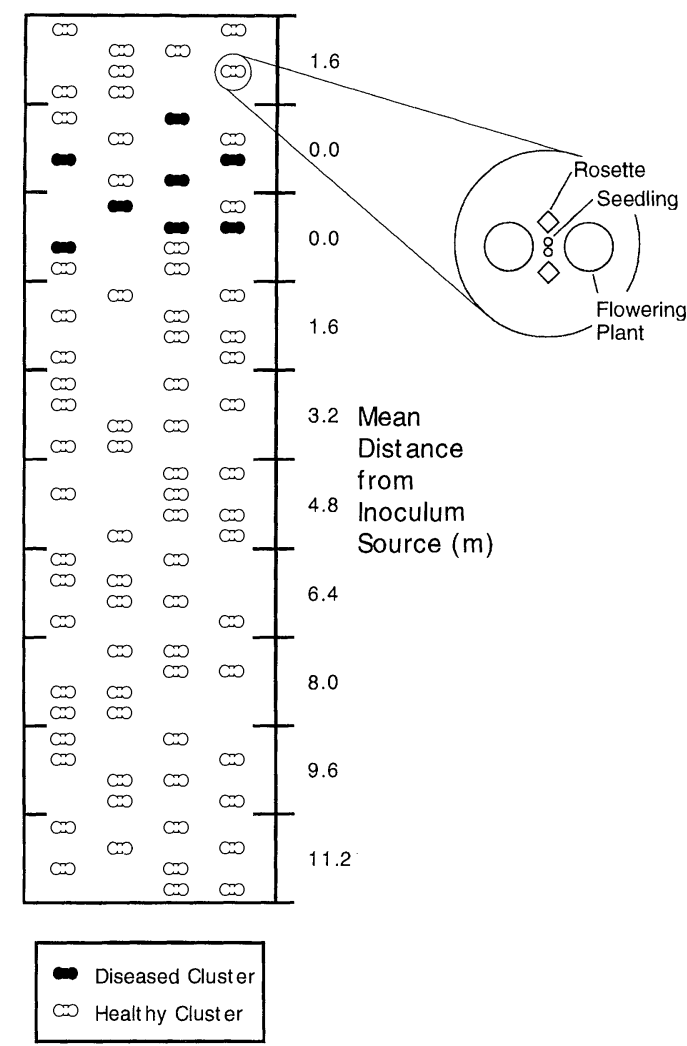

FIG. 1. Layout of experimental population. Filled circles represent diseased flowering plants. Open circles represent healthy flowering plants. Pairs of healthy seedlings and rosettes were associated with each pair of diseased or healthy flowering plants. Rows and columns are $0.4 \mathrm{~m}$ apart.

odology was adapted from Alexander and Antonovics (1988) and Alexander (1990b).

To avoid production of secondary disease foci, all flowering plants that produced diseased flowers were removed and replaced with healthy plants. The frequency of infection of flowering plants at each distance for each of the four gradients was calculated as the proportion of flowering plants which became diseased in a four-row zone. The small total number of infections required combining the results from males and females. Vegetative plants that flowered by September 1991 were assigned fates (healthy or diseased) or dropped from the analysis if they did not flower. Frequency of vegetative infection at each distance was calculated as the proportion of seedlings and rosettes (pooled) that became diseased in a four-row zone.

\section{Statistical analysis}

Gradients were oriented in various directions with respect to wind direction to reduce the chance of any directional bias in spore dispersal due to either airborne spores or spores carried by insects moving along air currents. To determine whether there was consistent directional bias within gradients, we used orthogonal 

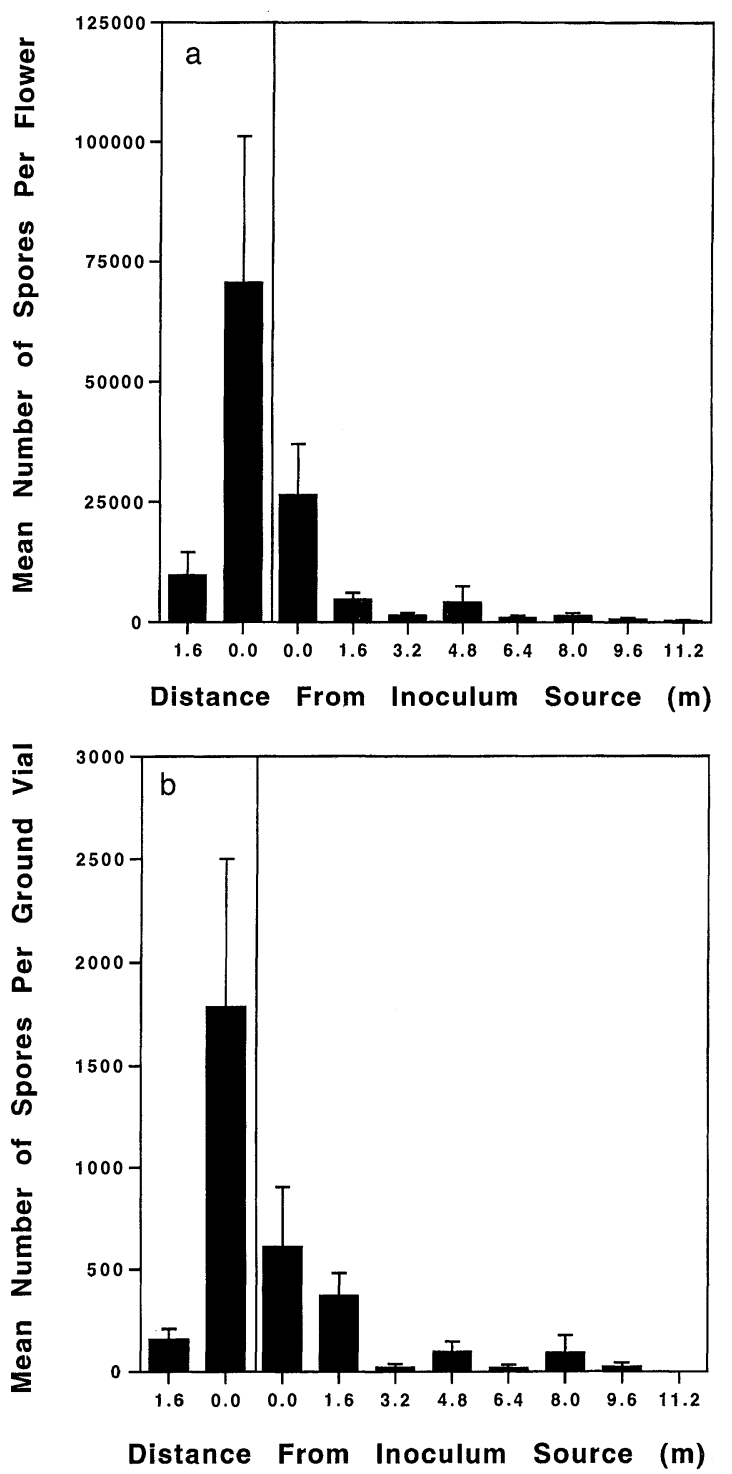

FIG. 2. Mean number of spores ( $\pm 1 \mathrm{SE}$ ) on (a) test flowers and (b) ground vials at each distance from the inoculum source. The two replicate disease zones (distance $=0.0 \mathrm{~m}$ ) and two replicate zones adjacent to disease zones (distance $=1.6 \mathrm{~m}$ ) are each shown separately.

linear contrasts to compare mean number of spores deposited in the replicate zones within each gradient (Contrast A-Disease Zones: zone 2 vs. zone 3; Contrast B-Adjacent to Disease Zones: zone 1 vs. zone 4).

We used regression analysis to look at the relationship between distance and either spore deposition or disease incidence. Two common models used to describe distance decay processes are the power law $(Y$ $\left.=a D^{-b}\right)$ and the exponential law $\left(Y=c e^{-g D}\right)$, where $D$ is distance from inoculum source and $Y$ can represent either the mean number of spores per flower or the probability of infection (Gregory 1968, Jeger 1990). Using linear regression on the log-transformed models, we always found that the power law was the better of the two modes (i.e., had the smaller residual mean square). To avoid the technical problems associated with taking the $\log$ of zero, one was added to each value before the log transformation. We did not detect any nonrandom patterns in plots of the residuals from the regressions.

To look at whether the sex of the plant or census date affected the relationship between proportion of flowers with spores and distance from inoculum source, we tested for a difference in slopes and intercepts of the regressions using analysis of covariance (Proc GLM; SAS 1988). Variances were heteroscedastic for spore deposition on males as compared to females, so we used an approximate studentized $t$ test for comparing two means with unequal variances (Sokal and Rohlf 1981) to determine whether mean spore deposition differed for males and females within each zone. Unless specifically noted, there were no significant effects of sex and census date on the dependent variables measured and thus these factors are not discussed further.

We present regression analyses based on data sets consisting of one value per four-row zone. We averaged or pooled across gradients since initial analysis of covariance revealed no significant differences among slopes for the four gradients. Within each zone, frequency data (presented as proportions) were first pooled over date and sex (for flowering plants) or vegetative stage (for vegetative plants) within each gradient, and results are presented as means across replicate gradients. Analogously, for mean number of spores, means were first taken across data and sex (for flowering plants) or vegetative stage (for vegetative plants) within each gradient, and results are presented as means across gradients.

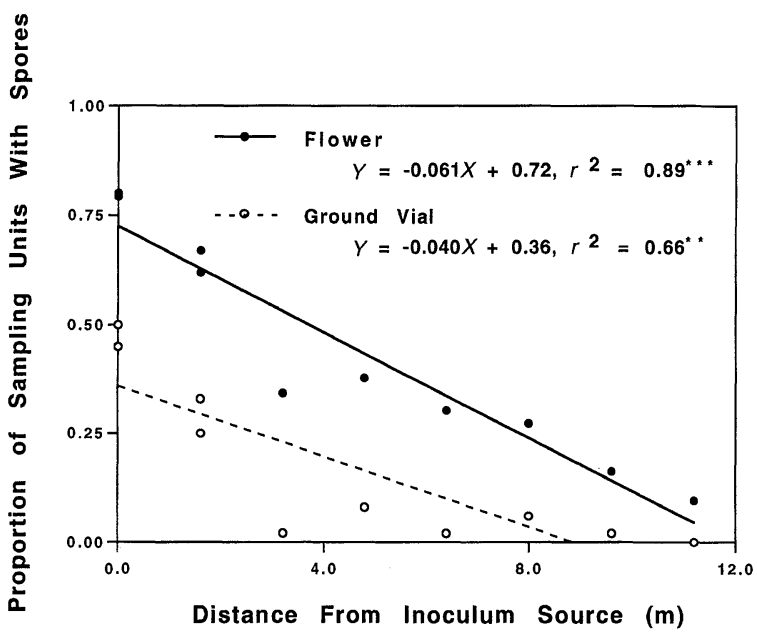

FIG. 3. Regressions of the proportion of sampling units with spores on distance from inoculum source, where sampling units are either test flowers $(-,-)$ or ground vials $(\bigcirc,---)$. ***P $<0.001, * * P<0.01$. 


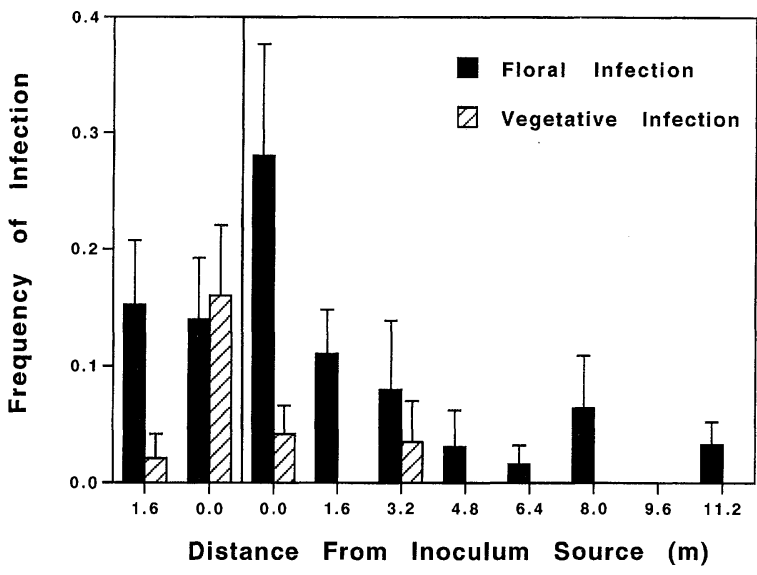

FIG. 4. Frequency $( \pm 1 \mathrm{SE})$ of floral infection and vegetative infection at each distance. The two replicate disease zones (distance $=0.0 \mathrm{~m}$ ) and two replicate zones adjacent to disease zones (distance $=1.6 \mathrm{~m}$ ) are each shown separately. Frequencies are presented as proportions.

\section{RESULTS}

\section{Directionality of spore dispersal}

For ground vials, neither contrast was significant for either of the two gradients ( 2 and 4 ) in which spores were counted. For flowers, neither contrast was significant in two of the gradients (1 and 4). Contrast A was significant for the other two gradients, but since Contrast B was not significant we concluded that there was no consistent directional bias in any of the gradients. Using visual inspection, we found that spore deposition patterns for all gradients were qualitatively similar.

\section{Spore dispersal and disease incidence for flowering plants}

We found a nonlinear relationship between spore deposition on flowers and distance from the inoculum source (Fig. 2a). The slope of the regression of $\log _{10^{-}}$ transformed mean number of spores per flower on $\log _{10^{-}}$ transformed distance from the inoculum source was $b$ $=-2.21\left(r^{2}=0.94, P<0.001\right)$. The relationship between proportion of flowers with spores and distance from inoculum source is linear (Fig. 3); proportions ranged from $7.6 \%$ of flowers with spores in the zone farthest from the inoculum source to $81 \%$ of flowers with spores in the diseased zone. There was a significant effect of census date on the intercept but not the slope for the relationship between proportion of flowers with spores and distance (slopes: $F_{3,32}=2.58, P=$ 0.07; intercepts: $\left.F_{3,32}=4.90, P<0.01\right)$. However, there was no seasonal trend to the difference in intercepts, so we averaged over census date for other analyses using proportion of flowers with spores.

The proportion of infected plants declines with distance from the inoculum source (Fig. 4). Tester and nontester plants did not differ in infection rates (tester:
$7.5 \%$; nontester: $8.1 \% ; \chi^{2}=.06, \mathrm{df}=1$, NS) and were thus combined for analyses involving disease incidence. The infection rate for flowering plants over all distances combined was $7.8 \%$ (40 infected plants $/ 513$ plants with known fates). The regression of $\log _{10}$-transformed frequency of disease incidence on $\log _{10}$-transformed distance averaging across experimental populations was significant $\left(r^{2}=0.70, P<0.01\right)$, and we estimated the slope parameter for this disease gradient as $b=-0.07$.

The relationship between frequency of infection and mean number of spores per flower is nonlinear, with limiting returns on infection as mean number of spores increases (Fig. 5a). We fitted a negative exponential function to the data using Proc NLIN (SAS 1988). The curve reaches an asymptote at $19 \%$ infection, and an increase in the number of spores deposited did not translate into an increased frequency of infection past $\approx 20000$ spores. Frequency of infection regressed on proportion of flowers with spores is linear (Fig. 6).
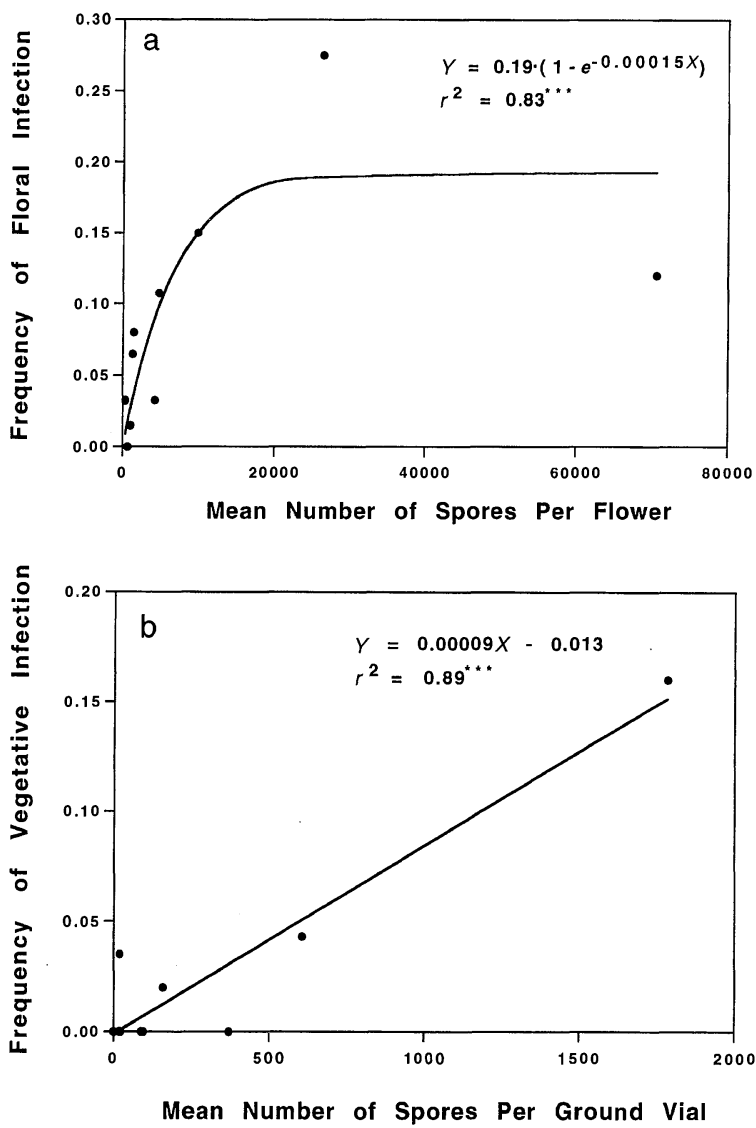

FIG. 5. (a) Frequency of floral infection as a function of mean number of spores per flower and (b) frequency of vegetative infection as a function of mean number of spores per ground vial. Each value represents the frequency (=proportion) of infection and mean number of spores at a given distance. $* * * P<0.001)$. 


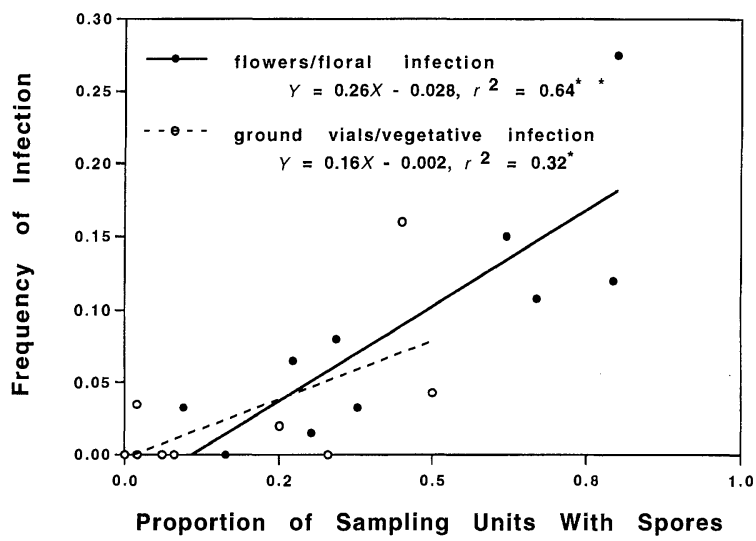

FIG. 6. Frequency (=proportion) of infection as a function of the proportion of sampling units with spores, where frequency of floral infection is regressed on proportion of test flowers with spores $(-,-)$, and frequency of vegetative infection is regressed on proportion of ground vials with spores $(\bigcirc,---)$. ${ }^{*} P<0.05,{ }^{*} P<<0.01$.).

\section{Spore dispersal on the ground and disease incidence for vegetative plants}

Spore deposition patterns on the ground as measured in ground vials revealed a pattern of high spore deposition very close to the source plants with negligible spore deposition farther away (Fig. 2b). The slope of the gradient for spore dispersal to the ground ( $b=$ $\left.-2.38, r^{2}=0.79, P<0.001\right)$ is not significantly different from the slope of the gradient for flowering plants $(b=-1.91)$, as revealed by analysis of covariance on $\log _{10}$-transformed mean number of spores per flower or ground vial and $\log _{10}$-transformed distance $\left(F_{1,16}=0.13, P=0.72\right)$. The relationship between our other measure of spore dispersal, proportion of ground vials with spores, is a linear function of distance from the inoculum source (Fig. 3). We compared regression lines by covariance analysis for proportion of flowers with spores and proportion of ground vials with spores as a function of distance and found that intercepts differed significantly but slopes did not (intercepts: $F_{1,16}$ $=37.52, P<0.0001$; slopes: $F_{1,16}=3.19, P<0.09$ ), with overall higher proportion of spore deposition on flowers than on the ground.

The infection rate for seedlings was $6.0 \%$ (6 infected seedlings out of 100 seedlings with known fates), while the infection rate for rosettes was only $1.4 \%$ ( 5 infected rosettes out of 347 with known fates). While we recognize a potential difference in infection frequencies for seedlings and rosettes, small sample sizes required that we combine them in all further analyses. The frequency of infection for all vegetative plants combined was $2.5 \%$ (11 infected plants/447 plants with known fates), while the frequency of infection for flowering plants was $8 \%$ (40 infected plants/513 plants with known fates). Vegetative infection was more spatially restricted than floral infection since no vegetative plants beyond $3.2 \mathrm{~m}$ from the inoculum source became infected (Fig. 4). In fact, 82\% (9/11) of all vegetative infections occurred within the disease zones, while only $32 \%(9 / 28)$ of infected male flowering plants and $58 \%(7 / 12)$ of infected female flowering plants occurred within these zones. The model for the regression of $\log _{10^{-}}$transformed frequency of infection on $\log _{10^{-}}$ transformed distance was not significant for vegetative plants, which precluded a statistical comparison of the slopes and intercepts of disease gradients for flowering and vegetative plants. The relationship between frequency of vegetative infection and mean number of spores on the ground (Fig. 5b) is linear. The relationship between proportion of ground vials with spores and frequency of infection was similar to that for proportion of flowers with spores and frequency of infection (Fig. 6), as neither the intercept nor the slope were significantly different for the two regression lines (for intercepts: $F_{1,16}=0.00, P=0.98$; for slopes: $F_{1,16}=$ 1.04, $P=0.32$ ).

\section{DISCUSSION}

\section{Patterns of spore dispersal and disease incidence}

We believe that anther-smut spore deposition on flowers is primarily due to the action of insect vectors; large numbers of $U$. violacea spores are reported on insects foraging in diseased populations (Jennersten 1988, Alexander 1990a). The range in numbers of spores deposited on healthy flowers by bumble bees after visiting diseased flowers in experimental arrays is consistent with natural levels of spore deposition of flowers (Alexander 1990b). In contrast, spore deposition to ground vials in our study is likely to be due to the passive settling of spores falling from diseased flowers or vector bodies. Certainly some passive spore dispersal to flowers may also occur. However, U. violacea spores were rarely detected in aerial spore traps $(0.3-0.5 \mathrm{~m}$ above ground level) located in diseased populations, as compared to large numbers of spores on healthy flowers at the same height (Jennersten 1988, Alexander 1990b, Antonovics and Alexander 1992). Furthermore, the large numbers of spores occasionally found on healthy flowers $10 \mathrm{~m}$ from infected plants (Alexander 1990b) cannot be explained by passive dispersal of spores through the air, but is entirely consistent with long-distance movement by insect vectors.

Spore deposition patterns were qualitatively similar for flowers and ground vials, with most of the spores deposited very close to the inoculum source and relatively few spores deposited further from the source. These patterns are similar to deposition gradients of aerially dispersed plant pathogens of crop plants (Gregory 1968, Kable et al. 1980, Schmidt et al. 1982, Aylor $1987)$ in that they are all described well by the power law. We expected the gradient for mean number of spores per ground vial to have a steeper slope than the gradient for mean number of spores per flower (Fig. 
$5 \mathrm{a}, \mathrm{b})$ because of the potential for longer distance movement of spores by vectors. However, the slopes for the dispersal gradients were not significantly different for ground vials and flowers. The similarity between dispersal gradients may be explained by vector activity. S. M. Altizer, P. H. Thrall, and J. Antonovics (unpublished manuscript) found that bumble bees deposited large numbers of spores on the first few healthy flowers visited subsequent to a visit to a diseased flower, but deposited low numbers of spores on the next 20 healthy flower visited. The pattern of decay for spores falling into vials on the ground may mirror the pattern of deposition on flowers. Our study did not allow for a comparison of absolute density of spores on vegetative parts of the plant vs. flowers, but we did find that the proportion of flowers with spores was higher than the proportion of ground vials with spores at every distance. This pattern provides additional evidence for the importance of insect vectors in the dispersal of anther-smut spores.

Disease incidence was much more localized for vegetative plants than for flowering plants, with disease limited to within $3.2 \mathrm{~m}$ from the inoculum source in vegetative plants while flowering plants became diseased up to the greatest distance possible in the experiment $(11.2 \mathrm{~m})$. Longer experimental gradients would have allowed us to develop a more complete picture of both spore dispersal and disease incidence. It is possible that we might have detected vegetative infections far from the inoculum source had we increased our sample size to counteract the low frequency of infections at early life stages. However, the higher percentage of vegetative infections in the disease zones ( $82 \%)$ compared to the percentage of floral infections in the disease zones ( $32 \%$ of males and $58 \%$ of females) provides evidence of more localized infection of vegetative plants. A similar steep disease gradient for vegetative plants was found by Alexander (1990b). The current study enabled us to directly compare disease incidence in vegetative and flowering plants exposed to identical sources of inoculum. Further studies should investigate disease incidence patterns under more natural relative densities of each stage.

Spore dispersal gradients and disease incidence gradients need not correspond to one another, as the conditions which are favorable for spore dispersal may not be favorable for infection (Johnson and Powelson 1983). We found that for both flowering and vegetative plants, the probability of disease increased linearly with proportion of flowers or ground vials with spores. We also observed a linear relationship between probability of vegetative infection and mean number of spores per ground vial. In contrast, we observed limiting returns on probability of infection with increasing mean number of spores per flower. Given the systemic nature of the disease, in theory only a single spore is needed to infect a plant. However, if spore deposition on a single flower is unlikely to lead to infection (because indi- vidual flowers may dehisce or be produced during times of unfavorable weather), infection is more likely if a high proportion of flowers on a plant receive spores. Increased spore deposition on a single flower also increases the likelihood of infection, but the curve quickly reaches an asymptote. We do not know whether there is a similar pattern of limiting returns on vegetative infection at higher levels of spore deposition. Given the time-consuming nature of spore deposition measurements, it is important to note that a simple measure of "presence/absence" of spores may provide nearly as much information about the expected disease levels as quantitative spore counts.

Our 1-yr study precludes an investigation of variation in spore deposition and disease incidence based on differences in weather conditions or assemblage of insect vectors among years. However, the patterns of spore deposition and disease incidence in flowering plants in our study were consistent with patterns observed by Alexander $(1990 b)$ in a natural linear population of $S$. alba in which diseased plants were introduced into the center of a previously entirely healthy population for four nights. The slopes of the gradients of mean number of spores on males $(b=-2.1)$ and females $(b=-1.1)$ in the natural population were similar in magnitude to the slope for males and females combined in this study $(b=-2.21)$. This increases our confidence that the patterns we detect in the experimental populations were relevant for extrapolation to natural linear populations. We constructed disease gradients for the natural population in 1987 and 1988 (Alexander $1990 \mathrm{~b}$ ) in order to make a quantitative comparison with the average disease gradient in the experimental populations. A comparison of slopes reveals slightly steeper slopes for disease gradients in the natural population $(1987: b=-0.09 ; 1988: b=-0.16$ ) compared to the average experimental population $(b=$ $-0.07)$. Note that no diseased plants were found beyond $7 \mathrm{~m}$ from the inoculum source in the natural population, whereas in the experimental populations, diseased plants were found up to $11.2 \mathrm{~m}$, the farthest distance possible.

While the similarities between spore dispersal and disease incidence patterns in our experiment and the natural population are striking, our results may be limited in scope to linear populations with similar proportions of diseased plants, and similar spatial distributions of healthy plants. Antonovics and Alexander (1992) showed experimentally that the frequency of diseased plants is a better predictor of spore deposition than density of diseased plants. Thus variance in the initial frequency of disease may alter the dispersal and disease gradients. Morris (1993) has demonstrated the importance of plant spacing on the development of pollen dispersal curves in honey-bee-pollinated mustard, with more shallow pollen gradients produced at higher degrees of spacing (with a concomitant lower density 
of plants). A similar effect of plant spacing on spore dispersal gradients is very likely.

Real et al. (1992) have developed spatially explicit models to explore the role of vector floral preference on disease spread within a population. With the empirical data presented here, such models could be made more realistic by including actual probabilities of spore dispersal and disease incidence at different distances from an inoculum source. Spatially explicit models of anther-smut at the metapopulation level have yielded important insight on regional persistence of host and pathogen (Antonovics et al. 1993). Models of local populations have not incorporated small-scale spatial patterns of spore dispersal and disease spread, but inclusion of such information could be important. Theoretical models predict that disease will often be lost from populations due to low rates of disease transmission (Thrall et al. 1994) or stochastic factors such as occasional high mortality of $S$. alba (Thrall and Jarosi 1994a). The incorporation of localized spore dispersal in these models could have potentially opposing consequences in terms of the rate of disease transmission. With a systemic infection like anther-smut, a plant is either healthy or infected, so deposition of increasing numbers of spores on plants near a cluster of diseased plants will eventually result in 'diminishing returns' in terms of numbers of new infections. Thus distancerestricted dispersal of spores could slow disease spread and make persistence of the pathogen even less likely. Increased aggregation of host plants led to decreased disease incidence in this system (A. Biere and J. Antonovics, unpublished data) and other systems (Mundt and Leonard 1985, Mundt et al. 1986, Dwyer 1991). However, clumping of diseased plants could enhance disease spread if it increased the number of flowers per plant that receive spores, since this increases the probability of successful infection (see Fig. 6). The relative importance of these opposing spatial phenomena on disease spread, and consequently on coexistence oi plant and pathogen, should be explored jointly with simulation models and with the establishment of ex perimental populations with different degrees of clumping of diseased plants.

\section{ACKNOWLEDGMENTS}

We would like to thank A. Reber, J. Delzer, and S. Martin for invaluable assistance in collecting the data. J. Antonovics, R. Holt, E. Marschall, S. Johnson, N. Slade, and P. Thrall all contributed extremely helpful comments to improve the pre sentation of this document. Research was funded by NSF Grant No. BSR-8505616 to H. M. Alexander and J. Antonovics, NSF Grant No. DEB-9119409 to H. M. Alexandeand P. V. Oudemans, a Pratt Fellowship from Mountain Lake Biological Station to B. M. Roche, and an NSF Dissertation Improvement Grant No. BSR-891044 to B. M. Roche.

\section{Literature Cited}

Alexander, H. M. 1989. An experimental field study of an ther-smut disease of Silene alba caused by Ustilago violacea: genotypic variation and disease incidence. Evolution 43:835-847. 1990a. Dynamics of plant-pathogen interactions in natural populations. Pages 31-45 in J. J. Burdon and S. R. Leather, editors. Pests, pathogens, and plant communities. Blackwell Scientific, Oxford, England.

- 1990b. Epidemiology of anther-smut infection of Silene alba caused by Ustilago violacea: patterns of spore deposition and disease incidence. Journal of Ecology 78: $166-179$.

Alexander, H. M., and J. Antonovics. 1988. Disease spread and population dynamics of anther-smut infection of Silene alba caused by the fungus Ustilago violacea. Journal of Ecology 76:91-104.

Antonovics, J., and H. M. Alexander. 1992. Epidemiology of anther-smut infection of Silene alba (=S. latifolia) caused by Ustilago violacea: patterns of spore deposition in experimental populations. Proceedings of the Royal Society of London B 250:157-163.

Antonovics, J., A. M. Jarosz, P. H. Thrall, and D. Stratton. 1993. Ecological genetics of metapopulations: the SileneUstilago plant-pathogen system. Pages 146-170 in L. Real, editor. Ecological genetics. Princeton University Press, Princeton, New Jersey, USA.

Aylor, D. E. 1987. Deposition gradients of urediniospores of Puccinia recondita near a source. Phytopathology 77: 1442-1448.

Augspurger, C. K. 1990. Spatial patterns of damping-off disease during seedling recruitment in tropical forests. Pages 131-144 in J. J. Burdon and S. R. Leather, editors. Pests, pathogens, and plant communities. Blackwell, Oxford, England.

Augspurger, C. K., and C. K. Kelly. 1984. Pathogen mortality of tropical tree seedlings: experimental studies of the effects of dispersal distance, seedling density, and light conditions. Oecologia 61:211-217.

Baker, H. G. 1947. Infection of species of Melandrium by Ustilago violacea (Pers.) Fuckel and the transmission of the resultant disease. Annals of Botany 11:333-348.

Burdon, J. J. 1987. Diseases and plant population biology. Cambridge University Press, Cambridge, England.

Dwyer, G. 1991. The roles of density, stage, and patchiness in the transmission of an insect virus. Ecology 72:559-574.

Fischer, G. W., and C. S. Holton. 1957. Biology and control of the smut fungi. Ronald, New York, New York, USA.

Gregory, P. H. 1968. Interpreting plant disease dispersal gradients. Annual Review of Phytopathology 6: 189-212.

Hassell, M. P., H. N. Comins, and R. M. May. 1991. Spatial structure and chaos in insect population dynamics. Nature 353:255-258.

Holt, R. D. 1993. Infectious diseases of wildlife, in theory and in practice. Trends in Ecology and Evolution 8:423425.

Jeger, M. J. 1990. Mathematical analysis and modeling of spatial aspects of plant disease epidemics. Pages 53-95 in J. Kranz, editor. Epidemics of plant diseases: mathematical analysis and modeling. Second edition. Springer-Verlag, New York, New York, USA.

Jennersten, O. 1988. Insect dispersal of fungal disease: effects of Ustilago infection on pollinator attraction in Viscaria vulgaris. Oikos 51:163-170.

Johnson, K. B., and M. L. Powelson. 1983. Analysis of spore dispersal gradients of Botrytis cinerea and gray mold disease gradients in snap beans. Phytopathology 73:741-746.

$\rightarrow$ Kable, P. F., P. M. Fried, and D. R. MacKenzie. 1980. The spread of powdery mildew of peach. Phytopathology $\mathbf{7 0}$ : 601-604.

McNeill, J. 1977. The biology of Canadian weeds. 25. Silene alba (Miller) E. H. L. Krause. Canadian Journal of Plant Science 57:1103-1114.

$\rightarrow$ Mollison, D. 1977. Spatial contact models for ecological and 
epidemic spread. Journal of the Royal Statistical Society, Series B, 39:283-326.

Morris, W. F. 1993. Predicting the consequences of plan spacing and biased movement for pollen dispersal by honey bees. Ecology 74:493-500.

$\rightarrow$ Mundt, C. C., and K. J. Leonard. 1985. Effect of host genotype unit area on epidemic development of crown rust following focal and general inoculations of mixtures of immune and susceptible oat plants. Phytopathology 75: 1141-1145.

$\rightarrow$ Mundt, C. C., K. J. Leonard, W. M. Thal, and J. H. Fulton. 1986. Computerized simulation of crown rust epidemics in mixtures of immune and susceptible oat plants with different genotype unit areas and spatial distributions of initial disease. Phytopathology 76:590-598.

Pielou, E. C. 1965. The spread of disease in patchily-infected forest stands. Forest Science 11:18-26.

Real, L. A., E. A. Marschall, and B. M. Roche. 1992. Individual behavior and pollination ecology: implications for the spread of sexually transmitted diseases. Pages 492-508 in D. L. DeAngelis and L. J. Gross, editors. Individual based models and approaches in ecology: populations communities, and ecosystems. Chapman and Hall, New York, New York, USA.
SAS. 1988. SAS/STAT user's guide. Release 6.03. SAS Institute, Cary, North Carolina, USA.

Schmidt, R. A., W. A. Carey, and C. A. Hollis. 1982. Disease gradients of fusiform rust on oak seedlings exposed to a natural source of aeciospore inoculum. Phytopathology 72: $1485-1489$.

Sokal, R. R., and F. J. Rohlf. 1981. Biometry: the principles and practice of statistics in biological research. Second edition. W. H. Freeman, San Francisco, California, USA.

Thrall, P. H., and A. M. Jarosz. 1994a. Host-pathogen dynamics in experimental populations of Silene alba and $U s$ tilago violacea. I. Ecological and genetic determinants of disease spread. Journal of Ecology, 82:549-559.

Thrall, P. H., and A. M. Jarosz. 1994b. Host-pathogen dynamics in experimental populations of Silene alba and Ustilago violacea. II. Experimental tests of theoretical models. Journal of Ecology, 82:561-570.

Thrall, P. H., A. Biere, and M. K. Uyenoyama. 1994. Frequency-dependent disease transmission and the dynamics of the Silene-Ustilago host-pathogen system. American Naturalist 145:43-62.

Tuite, J. 1969. Plant pathological methods of fungi and bacteria. Burgess, Minneapolis, Minnesota, USA.

van den Bosch, F., H. D. Frinkling, and J. A. J. Metz. 1988. Focus expansion in plant disease. III. Two experimental examples. Phytopathology 78:919-925. 